\title{
O USO DE COMUNIDADES DE PRÁTICA NA PRODUÇÃO DE MATERIAIS DIDÁTICOS PARA EDUCAÇÃO A DISTÂNCIA
}

\section{THE USE OF COMMUNITIES OF PRACTICE IN THE EDUCATIONAL MATERIALS PRODUCTION FOR E-LEARNING}

\author{
Dafne Fonseca Alarcon ${ }^{1}$, Dra. \\ Fernando José Spanhol ${ }^{2}$, Dr. \\ (1) Universidade do Estado de Santa Catarina \\ e-mail:dafnefa@gmail.com \\ (2) Universidade Federal de Santa Catarina \\ e-mail:profspanhol@gmail.com
}

Palavras-chave: Comunidades de Prática, Produção de Materiais Didáticos, Design Educacional.

O artigo tem como objetivo analisar a utilização, a relevância, frequência, aplicabilidade e o impacto das

Comunidades de Prática na produção de materiais didáticos para a Educação a Distância (EaD). A análise foi realizada por meio de questionário online com equipes multidisciplinares em (88) organizações que atuam na área da $\mathrm{EaD}$. Os resultados obtidos apontaram para a possibilidade de melhorias na utilização de CoPs em organizações que trabalham com Educação a Distância, a fim de, incentivar a participação de equipes multidisciplinares nas decisões do curso, propondo mudanças necessárias e melhorias ao processo de produção de materiais didáticos.

Key-words: Communities of Practice, Production of Educational Material Published, Educational Design.

The purpose of the article is to analyze the use, the relevance, the frequency, applicability and the impact of the Communities of Practice in the production of educational materials for E-learning. The analysis was performed using an online questionnaire with multidisciplinary teams in 88 organizations that work in the E-learning field. The results obtained pointed to the possibility of improvements in the use of CoPs in organizations that work with Distance Education, in order to encourage the participation of multidisciplinary teams in the course decisions, proposing necessary changes and improvements to the production process of didactic materials.

\section{Introdução}

A Sociedade do Conhecimento se caracteriza pelo excesso de informações e pela capacidade de pessoas e grupos de buscar, utilizar e compartilhar conhecimentos de forma dinâmica. Nesse cenário, organizações de diversos segmentos buscam agregar na Gestão do Conhecimento, o diferencial para a qualidade de seus processos e serviços, sendo o capital intelectual o recurso mais valioso a ser gerenciado, e onde o conhecimento torna-se fator decisivo para o sucesso (ALARCON; SPANHOL, 2015, P 23). O sucesso das organizações na Sociedade do Conhecimento se encontra na mobilização de seus ativos de conhecimento e na capacitação de seus 


\section{$16^{\circ}$ \\ ERGODESIGN USIHC CINAHPA}

$16^{\circ}$ Ergodesign - Congresso Internacional de Ergonomia e Usabilidade de Interfaces Humano Tecnológica: Produto, Informações Ambientes Construídos e Transporte

$16^{\circ}$ USIHC - Congresso Internacional de Ergonomia e Usabilidade de Interfaces Humano Computador

CINAHPA | 2017 - Congresso Internacional de Ambientes Hipermídia para Aprendizagem. colaboradores para enfrentar um novo ambiente de trabalho cada vez mais incerto e competitivo.

Nesse ambiente, a Gestão do Conhecimento (GC) fornece os métodos e ferramentas adequados para alavancar a aprendizagem e a inovação, sendo fundamental para o sucesso das organizações (BATISTA et. al., 2005). No entanto, para Alarcon e Spanhol (2015, p. 23) Práticas de Gestão do Conhecimento (PGCs) nem sempre são aderidas formalmente, em muitos casos, essas práticas são utilizadas informalmente, ou mesmo não são utilizadas em um procedimento formal para melhoria dos fluxos e compartilhamento do conhecimento organizacional. Em organizações que utilizam Educação a Distância (EaD), tanto públicas quanto privadas, a principal estratégia está focada na atualização constante do conhecimento, por meio da capacitação de seus colaboradores (equipe multidisciplinar e estudantes) para promover mudanças e inovação no ambiente educacional, diversificar as ofertas de seus serviços e atender as necessidades intensificadas pela economia do conhecimento (ALARCON, 2015 p. 23). Desta forma, a qualidade dos serviços de EaD precisam estar em consonância com a realidade e o contexto educacional e organizacional, atendendo as necessidades culturais, sociais e econômicas do ambiente onde irá atuar. Mesmo, havendo a constatação de resistências em torno da EaD, esta modalidade tem se mobilizado para adotar o uso intensivo dos diferentes recursos e tecnologias educacionais por meio de Ambientes Virtuais de Aprendizagem (AVAs) como possibilidade de oferta de uma "sala de aula virtual e interativa" (SILVA, 2001), que tem como objetivo facilitar o acompanhamento dos estudantes na realização das atividades de aprendizagem, no acesso aos materiais didáticos e objetos de aprendizagem. No caso das instituições públicas, o desafio está na expansão da educação no país e, nas empresas privadas, na busca crescente de adequação das necessidades de treinamento e desenvolvimento do mundo corporativo. (VALENTE; ARANTES, 2011). Considerando a Gestão do Conhecimento como uma prática essencial em organizações intensivas em conhecimento, como no caso das instituições de ensino e pesquisa e organizações que atuam na EaD, foi feito o levantamento e a análise descritiva do uso (formal e informal), a relevância, frequência, aplicabilidade e o impacto das Comunidades de Prática (CoPs) em organizações de EaD, considerada como uma Prática de Gestão do Conhecimento (PGC), que tem como princípio alargar e aprofundar o conhecimento por meio da aprendizagem social. A metodologia adotada para análise das CoPs no contexto de produção de materiais didáticos para $\mathrm{EaD}$ foi realizada por meio da estatística descritiva de caráter quali-quantitativo com aplicação de um questionário online ou método Survey para levantamento e análise dos dados.

\section{Características das CoPs}

As Comunidades de Prática (CoPs) são grupos de pessoas que compartilham uma preocupação ou um sentimento por algo que fazem e aprendem. No contexto da Gestão do Conhecimento, as CoPs são formadas intencionalmente ou de forma espontânea para compartilhar e criar habilidades comuns, conhecimento e experiência entre os participantes (APO, 2009). Formada por grupos de pessoas que compartilham uma preocupação ou um sentimento por algo que fazem e aprendem.

No contexto da Gestão do Conhecimento, as CoPs são formadas intencionalmente ou de forma espontânea para compartilhar e criar habilidades comuns, conhecimento e experiência entre os participantes (WENGER, 2004). Para Wenger (2002) esta prática é definida como um grupo de pessoas que interagem regularmente para compartilhar as mesmas práticas, interesses ou objetivos de trabalho com o objetivo de estudar como as pessoas aprendem. No entanto, para que alguém queira compartilhar algo com outra pessoa é fundamental que se perceba que haverá um benefício mútuo entre as partes. Por isso, as organizações precisam promover a criação de uma cultura de compartilhamento, ampliando o conhecimento organizacional por meio das CoPs. A Comunidade de Prática é uma relação entre pessoas que se dispõe a realizar uma atividade que os identifica de certo modo. Em outros termos, esta prática não requer a presença das pessoas de modo físico, mas exige que estejam interessadas em um certo domínio do conhecimento (WENGER, 2002; MOSER, 2012). Nas CoPs há uma veiculação e produção de conhecimentos que se processam
Realização:

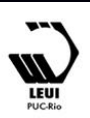




\section{$16^{\circ}$ \\ ERGODESIGN USIHC CINAHPA}

entre pares. Essas comunidades devem ser estruturadas segundo os três aspectos mencionados por Wenger (2002) e Moser (2012) que são:

a) DOMÍNIO que "cria uma base e um sentido de uma identidade comum" (WENGER, 2002, p. 27), no qual as equipes membros da comunidade poderão conversar e trocar ideias sobre as questões mais premente em relação ao processo de produção dos materiais. É importante que se defina bem o tema central a ser tratado, tais como: a publicação de disciplinas no AVA, a produção de livros didáticos, a criação de vídeos interativos, o design gráfico e educacional dos conteúdos, entre outros materiais didáticos.

b) A COMUNIDADE que vai "criar a fábrica social de aprendizagem. A comunidade se alimenta e se fundamenta em relações que devem ser baseadas no respeito e na confiança mútua" (WENGER, 2002, p. 28). A aprendizagem considerada como uma prática social não acontecerá se não houver dedicação e comprometimento dos envolvidos.

c) A PRÁTICA ó terceiro requisito no qual "a prática é o conhecimento específico que a comunidade desenvolve, compartilha e mantém" e para sua existência e manutenção se faz necessário o compartilhamento de um conjunto de referenciais, ideias, instrumentos, informações, estilos, linguagens e documentos entre os membros da comunidade (WENGER, 2002, p. 29).

No tocante, as equipes atuantes em organizações de $\mathrm{EaD}$ são formadas por equipes multidisciplinares que se caracterizam por suas diferentes especialidades e que precisam compartilhar conhecimentos no processo de produção dos materiais didáticos, que são eles: roteiros, vídeos e jogos educativos (objetos de aprendizagem) para alimentar os diferentes Ambientes Virtual de Aprendizagem - AVAs. Nesse sentido, o uso intensivo das tecnologias e mídias digitais gera a necessidade de criação de ambientes educacionais cada vez mais criativos e inovadores, cujo objetivo está na potencialização da aprendizagem e no atendimento de estudantes cada vez mais interativos e autônomos $16^{\circ}$ Ergodesign - Congresso Internacional de Ergonomia e Usabilidade de Interfaces Humano Tecnológica: Produto, Informações Ambientes Construídos e Transporte

$16^{\circ}$ USIHC - Congresso Internacional de Ergonomia e Usabilidade de Interfaces Humano Computador

CINAHPA | 2017 - Congresso Internacional de Ambientes Hipermídia para Aprendizagem.
(ALARCON, 2015). Porém, de acordo com Preece (2005) a principal barreira das equipes multidisciplinares está na dificuldade de interação entre os diferentes profissionais com formações variadas e as diferentes perspectivas de ver e dar significado ao mundo que os cercam. Porém, para a autora, ao mesmo tempo, reunir pessoas com formações e treinamentos variados, é extremamente produtivo, pois significa que muitas ideias estão sendo geradas e, novos métodos desenvolvidos e compartilhados Para Bejarano et. al., (2006) apesar do potencial criativo das equipes multidisciplinares, incluindo a produção de serviços e tecnologias educacionais, estas equipes possuem limitações que nem sempre podem ser superáveis. Entre elas, estão à dificuldade de conciliar a inclinação individualista com a disposição para trabalhar por um objetivo comum e a dificuldade de compartilhar conhecimento entre os membros e com os membros de outras equipes. Desta forma, é possível identificar a necessidade das equipes multidisciplinares (professores, tutores, conteudistas, designers educacionais, gráficos e estudantes) em compartilhar conhecimentos, tendo as CoPs como um elemento de gestão relevante na produção de materiais didáticos para $\mathrm{EaD}$.

\section{Processo de Design Educacional - ADDIE}

De acordo com Alarcon; Spanhol (2015, p. 45) o Modelo ADDIE por ser considerado um Sistema de Design Educacional de referência amplamente utilizado e construído em uma base teórica solidificada na literatura que tem por finalidade desenvolver produtos e serviços educacionais diversos. O Modelo ADDIE (Análise, Design, Desenvolvimento, Implementação e Avaliação) foi configurado como uma estrutura útil para examinar, criar, desenvolver e aplicar cursos de EaD. A Figura (01) ilustra as etapas do processo, a seguir (GUSTAFSON; BRANCH, 1997):

Realização:




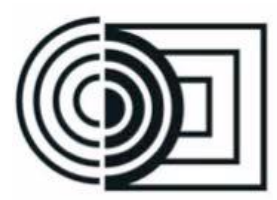

$16^{\circ}$ Ergodesign - Congresso Internacional de Ergonomia e Usabilidade de Interfaces Humano Tecnológica: Produto, Informações Ambientes Construídos e Transporte

$16^{\circ}$ USIHC - Congresso Internacional de Ergonomia e Usabilidade de Interfaces Humano Computador

CINAHPA | 2017 - Congresso Internacional de Ambientes Hipermídia para Aprendizagem.

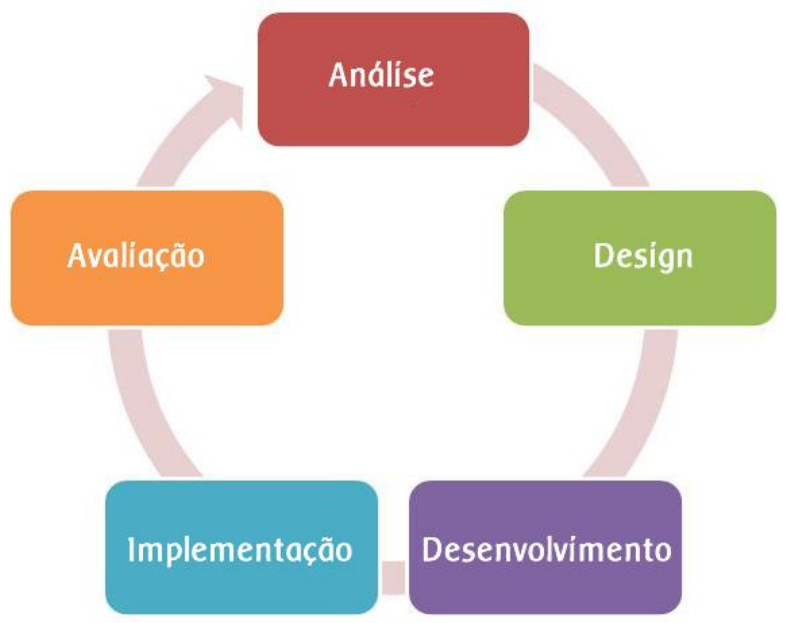

FIGURA 01 - Modelo ADDIE. Fonte: dos autores (1997).

Os detalhes de cada etapa do ADDIE estão dispostos a seguir conforme (MOLENDA, 2003; MAYFIELD, 2011):

\subsection{Análise}

Nesta etapa são definidos os objetivos e as estratégias de aprendizagem de acordo com o modelo de aprendizagem a ser concebido. Uma característica marcante dessa etapa são as metas específicas de aprendizagem que resultam do compartilhamento de competências, conhecimentos e habilidades envolvidas. Portanto, esta etapa requer recursos determinísticos de mineração do conhecimento disponíveis para a implantação do modelo de aprendizagem, de acordo com a caracterização dos participantes e métodos de entrega alternativos que inclui a definição do problema educacional para projetar uma solução aproximada. Isto é feito por meio da caracterização do perfil dos estudantes, levantamento das necessidades educacionais e formação da equipe multidisciplinar. Esta fase do processo fornece orientações claras sobre o que é necessário e o que é possível fazer no projeto. Quando algumas metas de aprendizagem não podem ser satisfeitas, novos recursos devem ser garantidos, ou objetivos de aprendizagem alterados.

\subsection{Design}

Esta etapa implica em definir as estratégias e atividades de aprendizagem, fazendo o mapeamento das atividades e o sequenciamento dos conteúdos, geralmente visualizados por meio de mapas conceituais e também é o momento de se fazer a escolha das mídias adequadas ao contexto de uso. Determinam os elementos educacionais que devem estar associados aos elementos conceituais do curso. Os elementos educacionais correspondem às informações complementares utilizadas na explicação de um dado conceito ou conjunto de conceitos. Esses elementos permitem que o aprendiz "navegue" através do domínio de conhecimento, praticando os conceitos abordados. Elementos de avaliação permitem que o desempenho do aprendiz e a consequente efetividade da solução seja determinada. Para cada elemento educacional, especificam-se os objetivos de aprendizado. Mídias apropriadas, bem como ferramentas e mecanismos de apoio também são especificados.

\subsection{Desenvolvimento}

Esta etapa trata das atividades que compõem o ciclo de vida do produto educacional e/ou material didático (digital ou impresso). Neste ponto podem ser identificadas as diferenças mais significativas entre produção de materiais e módulos educacionais. Nesta fase, os desenvolvedores criam o conteúdo de aprendizagem. Este conteúdo inclui o quadro geral de aprendizagem (pesquisa como um sistema de e-learning), exercícios, palestras, simulações ou outro material de treinamento adequado ao contexto. Esta etapa classifica o produto tangível a ser usado para o treinamento (livro didático, impresso e/ou digital, vídeo aulas, manuais etc..). É a oportunidade para se fazer as correções necessárias antes de entregar os módulos de aprendizagem. A tática útil nesta etapa é fazer um teste com os usuários para determinar se as metas de aprendizagem foram cumpridas e estão alinhadas as estratégias da etapa na etapa do design. 
$16^{\circ}$ Ergodesign - Congresso Internacional de Ergonomia e Usabilidade de Interfaces Humano Tecnológica: Produto, Informações Ambientes Construídos e Transporte

$16^{\circ}$ USIHC - Congresso Internacional de Ergonomia e Usabilidade de Interfaces Humano Computador

CINAHPA | 2017 - Congresso Internacional de Ambientes Hipermídia para Aprendizagem.

\subsection{Implementação}

Esta etapa solicita a participação dos estudantes para obtenção de feedbacks valiosos ao projeto. Esses feedbacks são contribuições ao processo de aprendizagem a distância. Os materiais didáticos são fornecidos aos estantes e o módulo de aprendizagem é utilizado para esta finalidade. A principal utilidade desta fase é a implementação do processo de aprendizagem. Sua relevância está na identificação de discrepâncias ou lacuna entre o desenvolvimento do conhecimento desejado e desenvolvimento real para implementar melhorias futuras. Filatro (2008) divide esta etapa em dois momentos distintos: a publicação do conteúdo no Ambiente Virtual de Aprendizagem e a execução, fase em que o estudante, já com seu acesso liberado ao ambiente de estudo, acessa os módulos e as unidades.

\subsection{Avaliação}

$\mathrm{Na}$ fase final do processo, os gestores avaliam os objetivos da aprendizagem, a eficiência das atividades, os problemas técnicos que dificultam a aprendizagem, bem como quaisquer novas oportunidades de aprendizagem identificadas. Esta fase é vital, porque fornece informações para melhorar a próxima iteração do programa de treinamento podendo sugerir novos caminhos e oportunidades ao curso. Define os ajustes finais de acordo com os feedbacks coletados revisando as estratégias para a condução da avaliação, a revisão da aprendizagem e o fechamento das atividades, dando início à gestão do curso. Para Mayfield, (2011) o modelo ADDIE é um processo colaborativo, que possibilita, por exemplo, que na etapa de design, a equipe possa obter um entendimento comum sobre a etapa posterior de desenvolvimento e interagir melhor, promovendo um processo de criação e compartilhada de conhecimentos. Além disso, por ser um processo iterativo o ADDIE auxilia na natureza de criação e distribuição de tarefas entre os membros da equipe. Desta forma, os diferentes atores podem estar em etapas específicas de criação, em vez de exigir que todos os criadores participem de todas as etapas e as habilidades de cada membro da equipe podem ser melhor aproveitadas no processo.

\section{A implementação de CoPs na produção de materiais didáticos}

As etapas analisadas incluem a possibilidade de implementação de CoPs em duas (2) ações e/ou atividades classificadas em (A) e (B) que são: a) as interações entre a equipe multidisciplinar na produção dos materiais didáticos; b) e a revisão das unidades publicadas no AVA, no qual inclui a publicação do curso propriamente dito que tem sua base de conhecimentos pautada nos feedbacks dos estudantes no sistema e o compartilhamento de conhecimentos para a solução de um determinado problema ou questão de interesse individual e/ou coletivo. Para identificar essas ações, foi necessária a montagem de um questionário online contendo dez (10) questões relacionadas aos critérios de: utilização, frequência, relevância, aplicabilidade (nas ações A e B) referentes ao processo de produção de materiais didáticos e o impacto das CoPs nesse processo (ALARCON, 2015, P.80). Para fins desta pesquisa, entende-se que as (10) questões envolvendo cada critério acima relacionado, tratam especificamente da implementação de CoPs no processo de produção de materiais didáticos, buscando analisar como esta prática pode auxiliar as equipes multidisciplinares na criação e compartilhamento de conhecimentos.

\section{Metodologia}

A pesquisa de caráter quantitativo requer o uso de recursos e técnicas estatísticas, o que significa traduzir em números, opiniões e informações para classificá-los e analisá-los (SILVESTRE, 2007). A ideia central de utilização de dados numéricos para a análise dos fenômenos está em acrescentar mais uma peça de evidencias ao corpo teórico com observações aproximadas da realidade (BRACARENSE, 2012). A análise estatística pode ser caracterizada como sendo descritiva ou inferencial, dependendo do método de coleta de dados e dos objetivos de análise. Para isso, é necessário ter uma compreensão da população e amostragem que serão introduzidas na pesquisa (SILVESTRE, 2007 p. 5).

Assim, a análise adotada foi a estatística descritiva, considerada como um conjunto de técnicas
Realização:

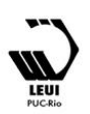




\section{$16^{\circ}$ \\ ERGODESIGN USIHC CINAHPA}

$16^{\circ}$ Ergodesign - Congresso Internacional de Ergonomia e Usabilidade de Interfaces Humano Tecnológica: Produto, Informações Ambientes Construídos e Transporte

$16^{\circ}$ USIHC - Congresso Internacional de Ergonomia e Usabilidade de Interfaces Humano Computador

CINAHPA | 2017 - Congresso Internacional de Ambientes Hipermídia para Aprendizagem. analíticas utilizadas para resumir o conjunto dos dados recolhidos em uma dada investigação. Estes dados são organizados, geralmente, em números, tabelas e gráficos, fornecendo relatórios com informações relevantes sobre a tendência central e a dispersão dos dados (MORAIS, 2005).

A coleta de dados de caráter transversal foi delimitada por um determinado período de tempo de (08) meses, no qual utilizou-se o instrumento em formato de um questionário eletrônico ou Survey para posteriormente, adotar o estudo qualitativo de análise dos dados por meio da estatística descritiva (BARBETTA, 2001). O público-alvo heterogêneo foi formado por conveniência com entrevistas feitas por equipes multidisciplinares em dois eventos do setor, no qual participaram (88) organizações (públicas e privadas) de $\mathrm{EaD}$. Os dois principais eventos da área de $\mathrm{EaD}$ onde houve coleta de dados presencial e online foram: ESUD 2014 - XI Congresso Brasileiro de Ensino Superior a Distância (evento nacional) e CIAED 2014 - Associação Brasileira de Educação a Distância, ABED (evento internacional) nas cidades de Florianópolis e Curitiba, respectivamente.

\section{Assim, a pesquisa foi dividida em cinco etapas descritas a seguir:}

1. Análise das Comunidades de Prática no contexto da Educação a Distância $(\mathrm{EaD})$, realizada através da Revisão da Literatura;

\section{Mapeamento do processo de produção de} materiais didáticos que descreve as ações e atividades em cada etapa do processo;

\section{Análise do compartilhamento do}

conhecimento das equipes multidisciplinares na produção de materiais didáticos;

\section{Aplicação do questionário online em} organizações e instituições privadas e públicas, e em dois eventos do setor para abordagem presencial que são: ESUD (Congresso Brasileiro de Ensino Superior a Distância) e ABED-CIAED (Congresso Internacional ABED);

\section{Descrição e análise dos dados coletados que}

foram gerados automaticamente em software específico para pesquisa quantitativa.

Para a elaboração do instrumento de pesquisa foi utilizado o referencial teórico e as categorias do framework da Manual da APO - Asian Productivity Organization (2009). Este Manual tem como objetivo apresentar as principais tendências na área de Gestão do Conhecimento em diversos países, tendo como base a premissa da relevância da GC para a economia global, em especial, para as pequenas e médias empresas. Dentre as práticas de GC propostas no Manual estão as CoPs que se apresentam como sendo uma prática bastante eficiente no compartilhamento de conhecimentos entre grupos. Para o processo de coleta de dados, definiu-se a técnica Survey, adotando o modelo de questionário eletrônico de auto aplicação como forma mais eficiente de alcançar uma quantidade significativa de participantes. $\mathrm{O}$ instrumento adotado foi adaptado para o contexto de pesquisa $\mathrm{e}$, posteriormente passou por um pré-teste para validação com (08) especialistas das áreas de GC e $\mathrm{EaD}$ e, após devidas correções, procedeu-se sua aplicação por meio eletrônico.

O questionário final ficou estruturado em um total de 63 questões no formato de entrevista estruturada e fechada. As questões se referem à aplicação de (10) PGCs selecionadas no processo de GC, conforme Manual da APO (2009) e (06) critérios conceituais de análise foram considerados, de acordo com o modelo de questionário adotado na pesquisa e avaliado junto com os especialistas.

Para este artigo, foi somente considerada PGC Comunidades de Prática contendo (06) questões específicas desta prática na produção de materiais didáticos para $\mathrm{EaD}$. Os critérios considerados foram: utilização formal e informal, frequência, relevância, aplicabilidade (A e B) referentes às ações mapeadas no processo (ADDIE) e o impacto das práticas de GC nos resultados do curso. A relação entre os critérios e o Modelo referenciado serviram como base para formulação do questionário ao mapear as atividades e ações inerentes em cada etapa do ADDIE. No caso das CoPs, a etapa elegida foi a de Implementação (conforme mostra o gráfico 4 e 5 no capítulo a seguir), no qual inclui a obtenção de feedbacks 


\section{$16^{\circ}$ \\ ERGODESIGN USIHC CINAHPA}

valiosos para o projeto do curso, a fim de propor e implementar melhorias. Os resultados são apresentados a seguir.

\section{Análise dos resultados}

De acordo com os resultados obtidos, as Comunidades de Prática (CoPs) são pouco utilizadas formalmente (26\%), nas organizações de $\mathrm{EaD}$ e utilizadas informalmente em (34\%) e não utilizadas $(26 \%)$, o que representa baixa adesão de acordo com o Gráfico (01).

\section{Esta prática é utilizada na organização?}

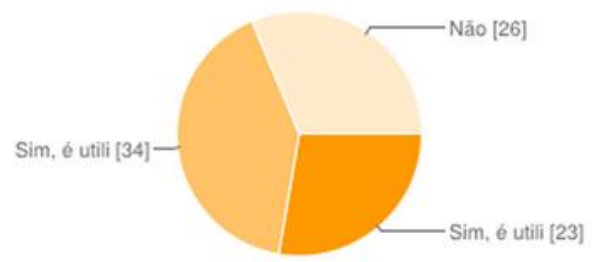

Gráfico 01. Utilização da prática na organização. Fonte: da autora (2014).

A frequência de uso da prática de CoPs teve maior ocorrência para o quesito "ás vezes" $(55 \%)$ esta prática ocorre na organização "sempre" (20\%) e "nunca" $(25 \%)$ - (Gráfico 02).

\section{Com que frequência essa prática ocorre?}

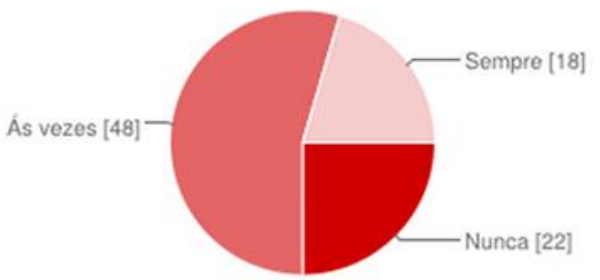

Gráfico 02. Frequência da prática na organização. Fonte: da autora (2014).

O critério de relevância não foi percebido pela maioria dos entrevistados ficando em alta relevância apenas (47\%), média relevância (39\%) e baixa relevância (15\%) (Gráfico 03). $16^{\circ}$ Ergodesign - Congresso Internacional de Ergonomia e Usabilidade de Interfaces Humano Tecnológica: Produto, Informações Ambientes Construídos e Transporte

$16^{\circ}$ USIHC - Congresso Internacional de Ergonomia e Usabilidade de Interfaces Humano Computador

CINAHPA | 2017 - Congresso Internacional de Ambientes Hipermídia para Aprendizagem.

(1)

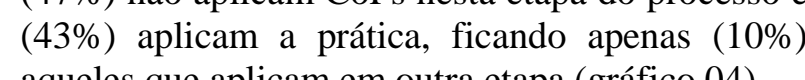
aqueles que aplicam em outra etapa (gráfico 04 ).

\section{CoPs são utilizadas na etapa de implementação (A)?}

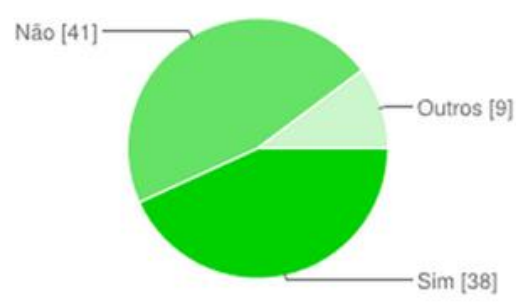

Gráfico 04. Aplicabilidade (A) da prática na organização. Fonte: da autora (2014).

A etapa de implementação inclui a análise das Interações Humano-Computador (IHC) que tem sua base de conhecimentos pautada nas tarefas e atividades do usuário no sistema, sendo a usabilidade o elemento-chave de fundamental importância para a funcionalidade das interfaces dos ambientes de aprendizagem (PREECE, 1994; DIX, 2009).

Com a finalidade de facilitar esta etapa do processo (Modelo ADDIE - Implementação) é que a Comunidade de Prática vem se destacando como uma forma de promover o aprendizado organizacional, agregando ferramentas necessárias para incentivar o compartilhamento de experiências, conhecimentos e soluções entre indivíduos para solucionar problemas no desenvolvimento de suas atividades (GOUVEA et. al., 2008).

Para o critério de aplicabilidade (B) - etapa de implementação para revisar as unidades publicadas 


\section{$16^{\circ}$ \\ ERGODESIGN USIHC CINAHPA}

$16^{\circ}$ Ergodesign - Congresso Internacional de Ergonomia e Usabilidade de Interfaces Humano Tecnológica: Produto, Informações Ambientes Construídos e Transporte

$16^{\circ}$ USIHC - Congresso Internacional de Ergonomia e Usabilidade de Interfaces Humano Computador

CINAHPA | 2017 - Congresso Internacional de Ambientes Hipermídia para Aprendizagem. no AVA a maioria também (48\%) afirmou não aplicar comunidade de prática nesta etapa do processo, quase metade $(45 \%)$ afirmaram aplicar e apenas (7\%) em outra etapa (Gráfico 05).

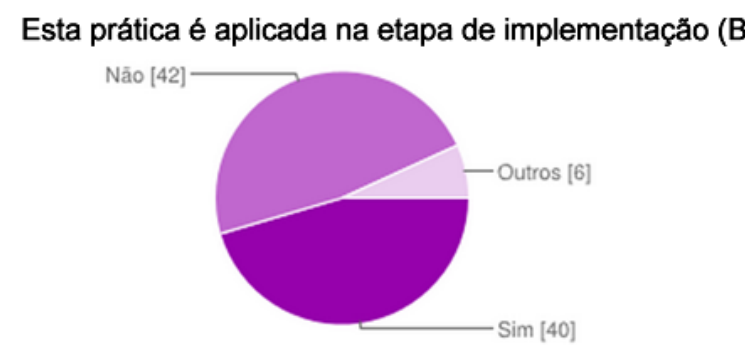

Gráfico 05. Aplicabilidade (B) da prática na organização. Fonte: da autora (2014).

A etapa de Implementação do Modelo ADDIE tem a função de revisar as unidades publicadas no AVA, no qual inclui a publicação do curso propriamente dito, o que significa que é necessário a obtenção de feedbacks dos participantes do curso (alunos, professores, tutores, designers) para compartilhar conhecimento, ou seja, trocar ideias, firmar compromissos, armazenar memórias, e recursos comuns para a solução de um determinado problema ou questão de interesse individual ou coletivo (GOUVEA et. al., 2008).

O impacto da prática de utilização de CoPs nos resultados do curso é considerado na percepção da maioria dos especialistas ficando em médio impacto (62\%) para os valores (4) e (3); baixo impacto (11\%) e nulo (6\%) de acordo com o Gráfico (06).

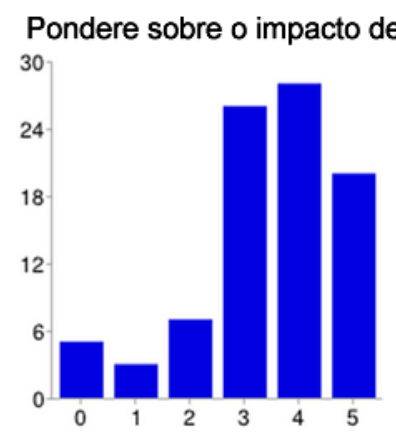

Gráfico 06. Grau de impacto da prática no resultado do curso. Fonte: da autora (2014).

O Gráfico (07), a seguir mostra o resultado geral da prática de CoPs e a baixa adesão da mesma no contexto da EaD.

Gráfico 07. Etapa de análise de CoPs.

\section{COMUNIDADE DE PRÁTICA}

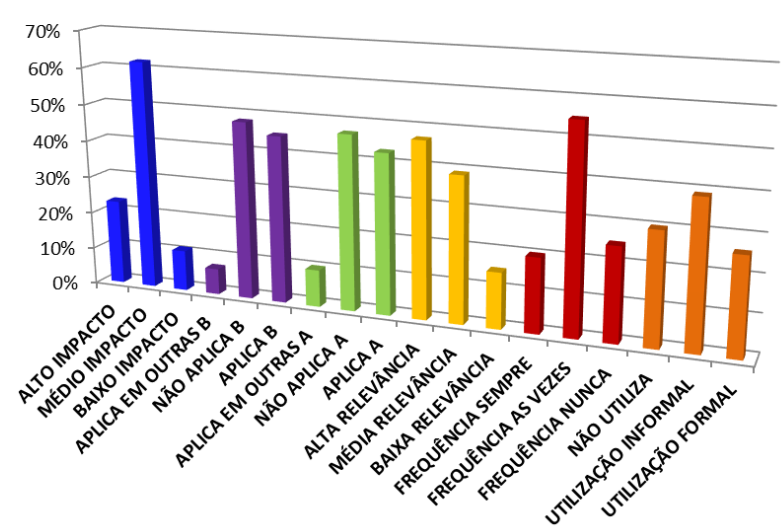

Fonte: dos autores (2015).

Os dados coletados sobre a prática geram uma contradição, pois apresentam baixa utilização formal da prática e alta percepção da relevância, ou seja, usam pouco mas entendem sua relevância sobre o impacto e os benefícios reais gerados pelas CoPs na produção de materiais didáticos para EaD.

Desta forma, é possível apontar para uma melhor aplicação desta prática em organizações e instituições, que utilizam ou pretendem utilizar $\mathrm{EaD}$, com a finalidade de impulsionar, incentivar e reconhecer a participação dos integrantes do curso (equipe multidisciplinar), envolvendo-os nas decisões relevantes, solucionando problemas e propondo mudanças necessárias e melhorias ao processo de produção de materiais didáticos.

\section{Considerações finais}

$\mathrm{O}$ artigo buscou analisar as Práticas de Gestão do Conhecimento com foco nas Comunidades de Prática, a fim de verificar sua utilização (formal e informal), a relevância, frequência, aplicabilidade e o impacto desta prática no processo de produção de materiais didáticos para $\mathrm{EaD}$.

Os resultados obtidos nas entrevistas e nas coletas de dados confirmam que as Comunidades de Prática, apesar do entendimento de sua relevância
Realização:
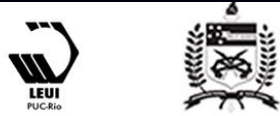


\section{$16^{\circ}$ \\ ERGODESIGN USIHC CINAHPA}

para a maioria dos entrevistados, está é ainda pouco utilizada formalmente em organizações que trabalham com $\mathrm{EaD}$ (utilizada informalmente $34 \%$ e não utilizada 26\%). $O$ entendimento sobre o que é a prática, como funciona e seus benefícios para criatividade e inovação de produtos e serviços educacionais é ainda incipiente, principalmente quando se trata da interação entre equipes multidisciplinares, no qual atuam diferentes especialidades e onde a dificuldade em compartilhar conhecimento ainda é uma barreira a ser superada.

Recomenda-se, a partir dos estudos aqui relatados que seja feita uma pesquisa qualitativa mais aprofundada e avançada sobre a utilização de Comunidades de Prática, apresentando os reais benefícios e melhorias que esta prática pode atribuir para o compartilhamento de conhecimentos na produção de materiais didáticos, e que não estão claramente percebidas ou mensuradas para sua plena utilização e para ampliação e dinamização do conhecimento existente, compartilhando experiências, conhecimentos e habilidades em torno de interesses comuns de especialistas, docentes, tutores e designers educacionais.

\section{BIBLIOGRAFIA}

ALARCON, Dafne F.; SPANHOL, Fernando José. Gestão do conhecimento na educação a distância: práticas para o sucesso. Pimenta Cultural, 2015.

APO. Knowledge management: Facilitator's Guide, 2009. Disponível em: <http://www.apotokyo.org/00e-books/IS-39_APO-KM-FG.htm> Acessado em: 9 dez. 2013.

BATISTA, F. F.; PACHECO F. F.; TERRA J. C. C. Gestão do conhecimento na administração pública. Brasília: Instituto de Pesquisa Econômica Aplicada/IPEA, 2005.

BEJARANO, V. C., PILATTI, L. A., DE CARVALHO, H. G., \& DE OLIVEIRA, A. C. Equipes e comunidades de prática como estruturas $16^{\circ}$ Ergodesign - Congresso Internacional de Ergonomia e Usabilidade de Interfaces Humano Tecnológica: Produto, Informações Ambientes Construídos e Transporte

$16^{\circ}$ USIHC - Congresso Internacional de Ergonomia e Usabilidade de Interfaces Humano Computador

CINAHPA | 2017 - Congresso Internacional de Ambientes Hipermídia para Aprendizagem.

complementares na gestão do conhecimento organizacional. Journal of Technology Management \& Innovation, v. 1, n. 3, p. 100106, 2006.

BRACARENSE, Paulo Afonso. Estatística aplicada às Ciências Sociais. IESDE Curitiba: Brasil, S.A, 2012.

FILARO, Andrea. Design instrucional na prática. São Paulo: Pearson Education do Brasil, 2008.

GIL, Antonio Carlos. Como elaborar projetos de pesquisa. São Paulo: Atlas, 1991.

GOUVÊA DA COSTA; S.E.; JARA, Jaime; SÓRIA, Miguel. A. Z. TORALES, Rubén D. G. Alinhando a gestão do conhecimento com a estratégia da empresa: o caso Itaipu binacional. In: VI Seminário da Gestão da Informação e do Conhecimento no Setor de Energia Elétrica. SINCONEE. Recife. 2005.

GUSTAFSON, Kent L.; BRANCH, Robert Maribe. Survey of instructional development models. Information Resources Publications, Syracuse University, 4-194 Center for Science and Technology, Syracuse, NY 13244-4100. 1997.

MAYFIELD, M. Creating training and development programs: using the ADDIE method, development and learning in organizations, Vol. 25 Iss: 3 pp. $19-22.2011$.

MOLENDA, Michael. In search of the elusive ADDIE model. Performance improvement, v. 42, n. 5, p. 34-37, 2003.

MORAIS, Carlos. Escalas de medida, estatística descritiva e inferência estatística. Escola Superior de Educação. Instituto Politécnico de Bragança. 2005.

MOSER, Alvino. Formação docente em comunidades de prática. Revista Intersaberes, v. 5, n. 10, p. 210-244, 2012.

PREECE, Jenny; ROGERS, Yvonne; SHARP, Helen. Design de Interação. Grupo A, 2005. SILVA, Marco. Sala de aula interativa: a educação
Realização:

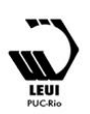




\section{$16^{\circ}$ \\ ERGODESIGN USIHC CINAHPA}

$16^{\circ}$ Ergodesign - Congresso Internacional de Ergonomia e Usabilidade de Interfaces Humano Tecnológica: Produto, Informações Ambientes Construídos e Transporte

$16^{\circ}$ USIHC - Congresso Internacional de Ergonomia e Usabilidade de Interfaces Humano Computador

CINAHPA | 2017 - Congresso Internacional de Ambientes Hipermídia para Aprendizagem.

presencial e a distância em sintonia com a era digital e com a cidadania. Boletim Técnico do SENAC, v. 27, n. 2, 2001.

VALENTE, José Armando; Moran José Manuel; ARANTES, V. A. Educação a Distância: pontos e contrapontos. 1. ed. São Paulo: Summus Editora, 2011. v. 1. 134p . 2011.

WENGER, E., MCDERMOTT, R. e SNYDER, W. M. Cultivating Communities of Practice. U.S.A.: Harvard University Press. 2002. 